\title{
The effect of an educational program using immediate and postponed feedback to learning breast stroke "Dr/ Mohamed A. Makled
}

Abstract

This study is an attempt to identify on the effect of immediate and postponed feedback to learning breast stroke for buds; the researcher used the experimental method using the experimental design of four groups

Use a sample of (28) buds, divided into four groups, equally each (9) buds at Delmon Sports Club in Benha.

- The first experimental sample: consisted of (7) bud, to study the program with immediate feedback.

- The second experimental sample: consisted of (7) bud, to study the program, postponed post-feedback after the educational unit.

- Third Pilot Sample: consisted of (7) bud to study the program by post-feedback and before the next unit

- Control sample: consisting of (7) buds, and they are studying using the verbal explanation from the teacher

The most important results

1- Immediate feedback is one of the best ways and means to use in teaching Brest stroke.

2- Postponed feedback to the next educational unit is better than postponed to the end of the educational unit

3- Postponed feedback to the end of the educational unit is better than traditional methods of teaching breast stroke

Key words: (feedback-Immediate feedback- Postponed feedbackbreast stroke )

\section{Introduction}

In swimming competitions, the swimmer advances through the water medium, relying on the tureens of the arms and legs of the legs to produce the driving force to overcome the water resistances that hinder the body's progress to cover the specified distances in the shortest possible time, so there is no way to do that except with technical performance consistent with mechanical and technical principles and principles through a codified training And a regular practice with correcting any errors that might hinder access to the method of correct technical performance. (Mohamed Ali al-Qat , 2000, p46)

* Dp. theories and applications of aquatic sports department Faculty of Physical Education for men Banha University .

Assiut Journal For Sport Science Arts 
And since the teaching methods vary according to the capabilities of the students, therefore, the methods that suit the needs of the pupils must be chosen by the effects of their motivation and the successful teacher is the one who can modify the students 'thinking and help them correct their mistakes so that in the day they reach the correct result and feedback is one of the methods that have the ability to Determining the learner's sufficiency and development, as well as enabling him to identify and correct his mistakes

Ashmawi,2006,p38)

The importance of feedback is due, in the eyes of many psychologists, to many considerations, foremost among which are the effects of the learner's motivation towards learning by completing the correct responses and avoiding the wrong response, and then it leads the learner to correct their wrong response, and is considered as an enhancement or confirmation of the correct responses. (Abdul Wahab Kamel,2011,p71)

Three main patterns of sensory feedback patterns come through what supplies the senses to the individual from knowledge of the individual and the second is feedback from the knowledge of the individual with a degree of information that helps him to understand the best situations and the third is feedback from knowledge of the results and the extent of success in performing the required work

\section{The feedback was rating} into:

1- Source of feedback (internal and external)

2- Synchronization with response (syndrome and final)

3- The time period between response occurrence and providing feedback (immediate - postponed).

4- Format of feedback information (verbal and written)

5- Distribution of feedback (separate and cumulative)

6- The amount of feedback (relative repetition and absolute repetition)

7- The nature of feedback (individual and social)

8- After the feedback (positive and negative)

9- Knowing the individual with some amount of information (qualitative and quantitative) 
10- Notifying the learner of the results of his performance (informative and corrective) (Magill, R.A,2001,p216)

And because feedback on different types, patterns, and many uses affects directly and clearly the educational process, it has become one of the best teaching methods and educational practices in classroom situations, so I entered the field of research and experiment. Several studies and researches were conducted to know their effectiveness in the performance of learners and their academic achievement and motivation for learning. (Siedentop, D. \& Eteal, 2004, p102)

\section{Research problem :}

The most important reasons that hinder the correct method of performance and lead to the appearance of errors, which are poor knowledge and understanding of the technical and special aspects (technical) and insufficient physical performance In light of this concept, it is necessary during the teaching and learning process in swimming to know the sequence of the movements to be performed and how to direct them with the assistance of building on the technical analysis of performance, which is intended to explain clearly the form and direction of movement performed by the swimmer, which aims to produce the final image of the performance The most economical of the movements to overcome the time factor (Ali Tawfiq,1996,p50)

And teaching breast stroke swimming to the buds in a correct way is a big challenge that requires the coach a great effort, as it is considered that breast stroke swimming skills are a complex skill for most young swimmers, and indicates that it must be realized that it needs a great time to learn and master well. (Sahar Abdulaziz, 2002, p75)

Swimming of the breast stroke is considered a difficult swimmer due to the difficulty of compatibility between the arms and legs, as the water component in it is large, which impedes the movement of the body forward, and the only swimming in which the two men have an effective role in it is considered to be equivalent to the effect of the arms on the movement of the body forward, and It is worth noting that the reactionary stage in breast 
stroke swimming is inside the aqueous medium, unlike the rest of the other methods of swimming in which the reactionary legs are outside the water, which increases the driving resistance of the swimmer during the performance (Mohamed Ali alQat , 2000, p95)

This difficulty in learning breast stroke swimming due to the high levels of harmony in the legs strokes and between the strokes of the men and arms in the breast stroke swim, which the researcher was invited to try to identify the impact of interest in the recurring nutrition in learning to swim in both types (immediate and postponed) and to know which is better in improving the level of swimming performance The breast stroke, in an effort by the researcher to provide a way that enables him to teach breast stroke swimming and gain a good performance in the least time and effort possible.

Aim of the research This study is an attempt to identify on the effect of immediate and postponed feedback to learning breast stroke for buds
Hypotheses: There are statistically significant differences at the level of significance 0.05 between the four groups (experimental 1, experimental 2 , experimental 3 , control) in the level of learning to swim in the buds and in favor of the post-measurement of the first experimental group.

\section{Method}

Design: The researcher used the experimental method using the experimental design of four experimental groups and a control group

sample : Use a sample of (28) buds, divided into four groups, equally each (9) buds at Delmon Sports Club in Benha.

- The first experimental sample: consisted of (7) bud, to study the program with immediate feedback.

- The second experimental sample: consisted of (7) bud, to study the program, postponed post-feedback after the educational unit.

- Third Pilot Sample: consisted of (7) bud to study the program by post-feedback and before the next unit

- Control sample: consisting of (7) buds, and they are studying using the verbal explanation from the teacher

Table (1)

Homogeneity of research personnel in anthropometric variables

Assiut Journal For Sport Science Arts 


\begin{tabular}{l|c|c|c|c}
\hline \hline & Mean & Median & Std. & Skew. \\
\hline \hline Age & 121.7143 & 120 & 9.64118 & -0.273 \\
\hline Length & 140 & 140 & 2.0367 & 0 \\
\hline the weight & 33.5357 & 33 & 2.54562 & 0.478 \\
\hline Training age & 34.0357 & 34 & 2.5889 & -0.042 \\
\hline Arm length & 62.9286 & 63 & 1.56178 & -0.564 \\
\hline Palm length & 15.8929 & 16 & 1.42307 & 0.119 \\
\hline Palm show & 6.5 & 6.5 & 1.13855 & 0 \\
\hline Thigh length & 40.3571 & 40 & 1.70434 & 0.118 \\
\hline Leg length & 38.0714 & 38 & 2.41797 & 0.249 \\
\hline Foot length & 19.3571 & 19 & 1.70434 & 0.118 \\
\hline Foot width & 7.8929 & 8 & 1.42307 & 0.119 \\
\hline Horizontal shoulder elasticity & 63.2143 & 63 & 2.31512 & 0.202 \\
\hline vertical shoulder elasticity & 21.8929 & 22 & 1.42307 & 0.119 \\
\hline \hline
\end{tabular}

Is evident from Table (1) that the torsion coefficient is limited between \pm 3 , the data is distributed naturally distribution suggesting homogeneity

Table (2)

Homogeneity of sample individuals researching skill variables

\begin{tabular}{l|c|c|c|c}
\hline \hline & Mean & Median & Std. & Skew. \\
\hline \hline Start & 3.6786 & 3.5 & 0.77237 & 0.646 \\
\hline The first 25 m & 4.3214 & 4 & 0.72283 & -0.584 \\
\hline Tureen & 4.5 & 4.5 & 0.83887 & 0 \\
\hline The second 25 m & 3.7857 & 4 & 0.56811 & -0.027 \\
\hline The end & 0.25 & 0 & 0.44096 & 1.221 \\
\hline Total & 16.5357 & 17 & 1.79469 & 0.517 \\
\hline \hline
\end{tabular}

Is evident from Table (2) that the torsion coefficient is limited between \pm 3 , the data is distributed naturally distribution suggesting homogeneity

Table (3)

Anova to four research groups in the anthropometric variables

\begin{tabular}{l|c|c|c|c|c|c}
\hline \hline & & Sum of squares & Df. & Mean squares & f. & Sig. \\
\hline \hline \multirow{3}{*}{ Age } & Between groups & 123.429 & 3 & 41.143 & 0.414 & 0.745 \\
\cline { 2 - 7 } & Within groups & 2386.286 & 24 & 99.429 & & \\
\cline { 2 - 7 } & total & 2509.714 & 27 & & & \\
\hline \multirow{3}{*}{ Training age } & Between groups & 0 & 3 & 0 & 0 & 1 \\
\cline { 2 - 7 } & Within groups & 112 & 24 & 4.667 & & \\
\cline { 2 - 7 } & total & 112 & 27 & & & \\
\hline \multirow{2}{*}{ the weight } & Between groups & 8.107 & 3 & 2.702 & 0.389 & 0.762 \\
\cline { 2 - 7 } & Within groups & 166.857 & 24 & 6.952 & & \\
\cline { 2 - 7 } & total & 174.964 & 27 & & & \\
\hline \hline
\end{tabular}

Follow Table (3)

Anova to four research groups in the anthropometric variables Assiut Journal For Sport Science Arts 


\begin{tabular}{|c|c|c|c|c|c|c|}
\hline 84 & & & & & & \\
\hline & & Sum of squares & Df. & Mean squares & f. & Sig. \\
\hline \multirow[t]{3}{*}{ Length } & Between groups & 1.536 & 3 & 0.512 & 0.068 & $\overline{0.976}$ \\
\hline & Within groups & 179.429 & 24 & 7.476 & & \\
\hline & total & 180.964 & 27 & & & \\
\hline \multirow[t]{3}{*}{ Arm length } & Between groups & 0.714 & 3 & 0.238 & 0.088 & 0.966 \\
\hline & Within groups & 65.143 & 24 & 2.714 & & \\
\hline & total & 65.857 & 27 & & & \\
\hline \multirow[t]{3}{*}{ Palm length } & Between groups & 2.964 & 3 & 0.988 & 0.459 & 0.714 \\
\hline & Within groups & 51.714 & 24 & 2.155 & & \\
\hline & total & 54.679 & 27 & & & \\
\hline \multirow[t]{3}{*}{ Palm show } & Between groups & 0.714 & 3 & 0.238 & 0.167 & 0.918 \\
\hline & Within groups & 34.286 & 24 & 1.429 & & \\
\hline & total & 35 & 27 & & & \\
\hline \multirow[t]{3}{*}{ Thigh length } & Between groups & 0.714 & 3 & 0.238 & 0.074 & 0.974 \\
\hline & Within groups & 77.714 & 24 & 3.238 & & \\
\hline & total & 78.429 & 27 & & & \\
\hline \multirow[t]{3}{*}{ Leg length } & Between groups & 12.714 & 3 & 4.238 & 0.701 & 0.561 \\
\hline & Within groups & 145.143 & 24 & 6.048 & & \\
\hline & total & 157.857 & 27 & & & \\
\hline \multirow{3}{*}{ Foot length } & Between groups & 0.714 & 3 & 0.238 & 0.074 & 0.974 \\
\hline & Within groups & 77.714 & 24 & 3.238 & & \\
\hline & total & 78.429 & 27 & & & \\
\hline \multirow[t]{3}{*}{ Foot width } & Between groups & 1.25 & 3 & 0.417 & 0.187 & 0.904 \\
\hline & Within groups & 53.429 & 24 & 2.226 & & \\
\hline & total & 54.679 & 27 & & & \\
\hline \multirow{3}{*}{$\begin{array}{l}\text { Horizontal shoulder } \\
\text { elasticity }\end{array}$} & Between groups & 0.714 & 3 & 0.238 & 0.04 & 0.989 \\
\hline & Within groups & 144 & 24 & 6 & & \\
\hline & total & 144.714 & 27 & & & \\
\hline \multirow{3}{*}{$\begin{array}{l}\text { vertical shoulder } \\
\text { elasticity }\end{array}$} & Between groups & 1.25 & 3 & 0.417 & 0.187 & 0.904 \\
\hline & Within groups & 53.429 & 24 & 2.226 & & \\
\hline & total & 54.679 & 27 & & & \\
\hline
\end{tabular}

Table (3) shows that the value of the calculated $p$ is greater than the value of the tabular and statistical significance is greater than 0.05 , which indicates that there

Table (4)

are no statistically significant differences at the level of significance 0.05 , which indicates the equivalence of the sample search anthropometric variables.

Anova for performance of swimming breast stroke

\begin{tabular}{|c|c|c|c|c|c|c|}
\hline & & Sum of squares & Df. & Mean squares & f. & Sig. \\
\hline \multirow[t]{3}{*}{ Start } & Between groups & 0.393 & 3 & 0.131 & 0.2 & 0.895 \\
\hline & Within groups & 15.714 & 24 & 0.655 & & \\
\hline & total & 16.107 & 27 & & & \\
\hline \multirow[t]{3}{*}{ The first $25 \mathrm{~m}$} & Between groups & 0.679 & 3 & 0.226 & 0.404 & 0.751 \\
\hline & Within groups & 13.429 & 24 & 0.56 & & \\
\hline & total & 14.107 & 27 & & & \\
\hline \multirow[t]{3}{*}{ Tureen } & Between groups & 0.429 & 3 & 0.143 & 0.185 & 0.906 \\
\hline & Within groups & 18.571 & 24 & 0.774 & & \\
\hline & total & 19 & 27 & & & \\
\hline
\end{tabular}

Follow Table (4)

Anova for performance of swimming breast stroke 


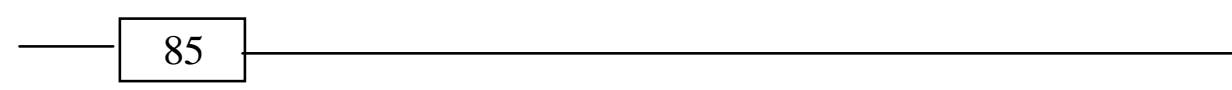

\begin{tabular}{l|l|c|c|c|c|c}
\hline \hline \multicolumn{2}{c|}{} & Sum of squares & Df. & Mean squares & f. & Sig. \\
\hline \hline \multirow{4}{*}{ The second 25 $\mathrm{m}$} & Between groups & 0.714 & 3 & 0.238 & 0.714 & 0.553 \\
\cline { 2 - 7 } & Within groups & 8 & 24 & 0.333 & & \\
\cline { 2 - 7 } & total & 8.714 & 27 & & & \\
\hline \multirow{3}{*}{ finish } & Between groups & 0.107 & 3 & 0.036 & 0.167 & 0.918 \\
\cline { 2 - 7 } & Within groups & 5.143 & 24 & 0.214 & & \\
\cline { 2 - 7 } & total & 5.25 & 27 & & & \\
\hline \multirow{2}{*}{ Total } & Between groups & 7.25 & 3 & 2.417 & 0.728 & 0.546 \\
\cline { 2 - 7 } & Within groups & 79.714 & 24 & 3.321 & & \\
\cline { 2 - 8 } & total & 86.964 & 27 & & & \\
\hline \hline
\end{tabular}

Table (4) shows that the value of the calculated $p$ is greater than the value of the tabular and the statistical significance is greater than 0.05 , which indicates that there are no statistically significant differences at the level of significance 0.05 , which indicates the equivalence of the sample search in the level of breast stroke swim performance

Data collection tools and means:

- A medical scale for measuring weight

- A two-pass device for measuring length

- The Maglecchio protractor to measure joint elasticity

- Swimming pool

- Floatation board

- Stand to carry the display screen

- Samsung 60 inch Smart Display

- 2 Canon cameras with high accuracy of photography and the possibility of connecting to the laptop wireless

- Laptop

- Program for viewing videos on the computer vc Media player

- A portable router that belongs to Vodafone

- Performance evaluation form for swimming breast stroke approved by the Egyptian Swimming Federation

- Dvr device to store videos

- Free Video Cutter

Steps to conduct a search

Preparing the educational program:

\section{The foundations of program} development:

The suitability of the program for the Sunni phase, and the use of some local and international programs that have been developed in that area, and the availability of the safety and security factor.

* Inclusiveness and balance of development of parts of the body so that no focus is placed on one part without the other. 
* Continuity and regularity so as not to lose the impact of previous exercises.

* The arrangement of the contents in the unit helps to achieve the best possible productivity to achieve its goals.

* One of the most important drivers of increased motivation is informing the individual of progress in his or her level first.

* The flexibility of the program to incorporate some of the loved elements into the soul away from boredom and monotony.

\section{Program design}

The researcher has access to the Internet (Internet) and research and studies related to the subject of research, as well as books and scientific references on the subject of research and the like, the researcher designed a form to specify the educational program attached () through the analysis of local and international programs such as:

The European-American Swimming Education Program. College Misericordia College program in Pennsylvania, USA.

* Australian Swimming Education Program.
* American Red Cross Program.

* IU American University Program.

* White University Program.

* 4 x $12=48$ hours swimming instruction program prepared by (Abu El-Ela Abdel Fattah).

The researcher reached to define the educational goals for each program, then set the educational goals and components of the educational program for breast stroke swimming, and they were presented to the experts, and then the researcher reached the components of the educational program

Duration of the program: one and a half months

Dental phase: Swimming buds from $(9-11)$ years.

Number of learning times per week: Two (2) educational lessons per week.

Unit time: (60 BC) hours per day.

Number of educational lessons: (13) an educational lesson distributed as follows:

* Introductory lesson (1) (first lesson).

* Lessons to teach the two men's skill (5) (from the second lesson to the eighth lesson). 
* Lessons for teaching farmers' skill (3) (ninth lesson).

* Lessons to teach arms movements and alignment with the legs of the two men (2) (tenth and eleventh lessons)

* Breathing and aligning with the movements of the arms and legs (1) (Lesson 12).

* Breathing and alignment with the movements of the arms and legs of the legs (complete breast stroke swimming performance) (1) (thirteenth lesson).

The 30-second video presentation period for the second experimental group to be displayed after the educational unit. The video display for the third experimental group to be displayed before the educational unit.

Videos of $30 \mathrm{~s}$ have been added to the first experimental group on the educational unit to be $120 \mathrm{~s}$, as the presentation will include inside the educational unit and after performing each exercise during the educational unit

Preparing feedback methods: 1- The researcher has prepared a number (13) video of performing the parts of the motor skill (buoyancy- the legs strokes- arm movements- compatibility- breathing- and the performance of swimming in full) under study and making sure of their clarity in the vision

2- The researcher equipped the Smart Display with its stand 3- The researcher prepared 2 cameras with their stand where one of them was installed with the width of the swimming pool and the second along the length of the bath and in the same field of performing buds for performance exercises.

4- Connecting the camera to a DVR device to record what is filmed during the educational unit and the ability to play back at different speeds

5- The researcher prepared a laptop with a video player program vc media player and a program to cut videos to smaller videos Free Video Cutter

\section{The Survey:}

The researcher conducted a survey study to make sure all the connections to the work unit, which consist of a camera connected to a power source and a DVR device to photograph and save with the ability to restart it on the display screen and linked to the laptop through the mobile $\mathrm{Wi}$ Fi network and confirmed the possibility of photography and display again and the 
possibility of display From the lab on the display screen for previously prepared videos, and the photography was based on one of the researcher's assistants, and the researcher was able to set all connections for the above mentioned devices, and they work efficiently and in the same field of the educational unit.

Tribal Measurement: The researcher conducted the premeasurement of the research sample on $27 / 5 / 2018$, for a group of anthropometric and skill measurements using three residents, where the score was calculated by taking the mean

\section{Basic experience}

The researcher conducted the basic study in the period from For the first experimental group: from $1 / 6 / 2018$ to $7 / 18 / 2018$ by performing the educational unit and inside it the researcher displays the video of each bud for him in front of the display screen then perform the video presentation to perform the proper after each performance with an explanation of the differences for the bud and then perform the skill again

For the second experimental group: from $2 / 6 / 2018$ to $7 / 19 / 2018$, by performing the educational unit, the researcher will photograph the performance of the students and then display the performance that was photographed after the completion of the educational unit with an explanation of the errors and display the videos that were prepared to perform the segmented motor skills to suit All alone and clarify the differences between bud performance and proper performance.

The third experimental group: from 3/6/2018 to $20 / 7 / 2018$, by performing the educational unit and photographing each bud in his performance during the unit and then displays the videos of each bud about the educational unit 1 for example before starting the educational unit 2 with clarifying the differences between the performance of the buds And proper performance.

Control group: From 4/6/2018 to 21/7/2018 where the researcher conducted the basic experiment with the traditional explanation.

\section{Dimensional measurement:}

The researcher made the dimensional measurements of the research samples as follows

The first experimental group is on $7 / 22 / 2018$

The second experimental group on $7 / 23 / 2018$

The third experimental group on $24 / 7 / 2018$

The control group was on 25/7/2018

It has to be in the same manner of performance and in the same conditions as for tribal measurement

Results 
Table (6)

ANOVA to Dimensional measurements of the four groups

\begin{tabular}{|c|c|c|c|c|c|c|}
\hline & & المزبعوع & الدرجيه & المربعات & قيمه ف & الدلاله \\
\hline \multirow[t]{3}{*}{ Start } & Between groups & 69.536 & 3 & 23.179 & 42.326 & .000 \\
\hline & Within groups & 13.143 & 24 & .548 & & \\
\hline & total & 82.679 & 27 & & & \\
\hline \multirow{3}{*}{ The first $25 \mathrm{~m}$} & Between groups & 74.964 & 3 & 24.988 & 58.306 & .000 \\
\hline & Within groups & 10.286 & 24 & .429 & & \\
\hline & total & 85.250 & 27 & & & \\
\hline \multirow{3}{*}{ Tureen } & Between groups & 70.143 & 3 & 23.381 & 39.280 & .000 \\
\hline & Within groups & 14.286 & 24 & .595 & & \\
\hline & total & 84.429 & 27 & & & \\
\hline \multirow{3}{*}{$\begin{array}{c}\text { The second } \\
25 \mathrm{~m}\end{array}$} & Between groups & 67.000 & 3 & 22.333 & 55.176 & .000 \\
\hline & Within groups & 9.714 & 24 & .405 & & \\
\hline & total & 76.714 & 27 & & & \\
\hline \multirow[t]{3}{*}{ finish } & Between groups & .107 & 3 & .036 & 1.000 & .410 \\
\hline & Within groups & .857 & 24 & .036 & & \\
\hline & total & .964 & 27 & & & \\
\hline \multirow[t]{3}{*}{ total } & Between groups & 1144.679 & 3 & 381.560 & 182.108 & .000 \\
\hline & Within groups & 50.286 & 24 & 2.095 & & \\
\hline & total & 1194.964 & 27 & & & \\
\hline
\end{tabular}

Table (6) shows that there are statistically significant differences at the level of significance 0.05 between the
Table (7)

dimensional measurements of the four groups except for the end of swimming breast stroke, there are no differences.

\section{L.S.D test between the four dimensional measurements}

\begin{tabular}{c|c|c|c|c|c|c}
\hline \hline & & mean & Std. & Experimental 2 & Experimental 3 & Control group \\
\hline \hline \multirow{5}{*}{ start } & Experimental 1 & 0.69 & 10.86 & -1.14 & 0.00 & -3.86 \\
\cline { 2 - 8 } & Experimental 2 & 0.76 & 9.71 & & 1.14 & -2.71 \\
\cline { 2 - 8 } & Experimental 3 & 0.69 & 10.86 & & & -3.86 \\
\cline { 2 - 8 } & Control group & 0.82 & 7.00 & & & \\
\hline \hline \multirow{5}{*}{ First25m } & Experimental 1 & 0.49 & 11.71 & -1.43 & -1.43 & -0.29 \\
\cline { 2 - 8 } & Experimental 2 & 0.76 & 10.29 & & 1.14 & -2.71 \\
\cline { 2 - 8 } & Experimental 3 & 0.79 & 11.43 & & & -3.86 \\
\cline { 2 - 8 } & Control group & 0.53 & 7.57 & & -0.29 & -4.00 \\
\hline \hline \multirow{5}{*}{ tureen } & Experimental 1 & 0.49 & 11.71 & -1.14 & 0.86 & -3.71 \\
\cline { 2 - 7 } & Experimental 2 & 0.98 & 10.57 & & & \\
\cline { 2 - 7 } & Experimental 3 & 0.79 & 11.43 & & & \\
\cline { 2 - 7 } & Control group & 0.76 & 7.71 & & & \\
\hline \hline
\end{tabular}

Follow Table (7)

L.S.D test between the four dimensional measurements

\begin{tabular}{c|c|c|c|c|c|c}
\hline \hline \multicolumn{2}{c|}{} & mean & Std. & Experimental 2 & Experimental 3 & Control group \\
\hline \hline The & Experimental 1 & 0.69 & 11.14 & -1.43 & -0.14 & -3.86 \\
\hline
\end{tabular}

Assiut Journal For Sport Science Arts 


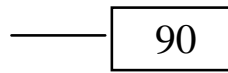

\begin{tabular}{|c|c|c|c|c|c|c|}
\hline \multirow{3}{*}{$\begin{array}{c}\text { second } \\
25 \mathrm{~m}\end{array}$} & Experimental 2 & 0.49 & 9.71 & & 1.29 & -2.43 \\
\hline & Experimental 3 & 0.82 & 11.00 & & & -3.71 \\
\hline & Control group & 0.49 & 7.29 & & & \\
\hline \multirow[b]{4}{*}{ finish } & Experimental 1 & 0.00 & 2.00 & 0.00 & 0.00 & -0.14 \\
\hline & Experimental 2 & 0.00 & 2.00 & & 0.00 & -0.14 \\
\hline & Experimental 3 & 0.00 & 2.00 & & & -0.14 \\
\hline & Control group & 0.38 & 1.86 & & & \\
\hline \multirow[b]{4}{*}{ total } & Experimental 1 & 0.98 & 47.43 & -5.14 & -0.71 & -16.00 \\
\hline & Experimental 2 & 1.80 & 42.29 & & 4.43 & -10.86 \\
\hline & Experimental 3 & 1.60 & 46.71 & & & -15.29 \\
\hline & Control group & 1.27 & 31.43 & & & \\
\hline \multicolumn{4}{|c|}{$\begin{array}{l}\text { Table (7) shows that there are } \\
\text { differences between all groups } \\
\text { except for experimental group }\end{array}$} & \multicolumn{3}{|c|}{$\begin{array}{l}\text { the absence of statistically } \\
\text { significant differences between } \\
\text { all groups at the end. }\end{array}$} \\
\hline
\end{tabular}

1 and experimental group 3 and

Table (8)

\section{percentage of improvement for the four groups in the level of breast stroke swim performance}

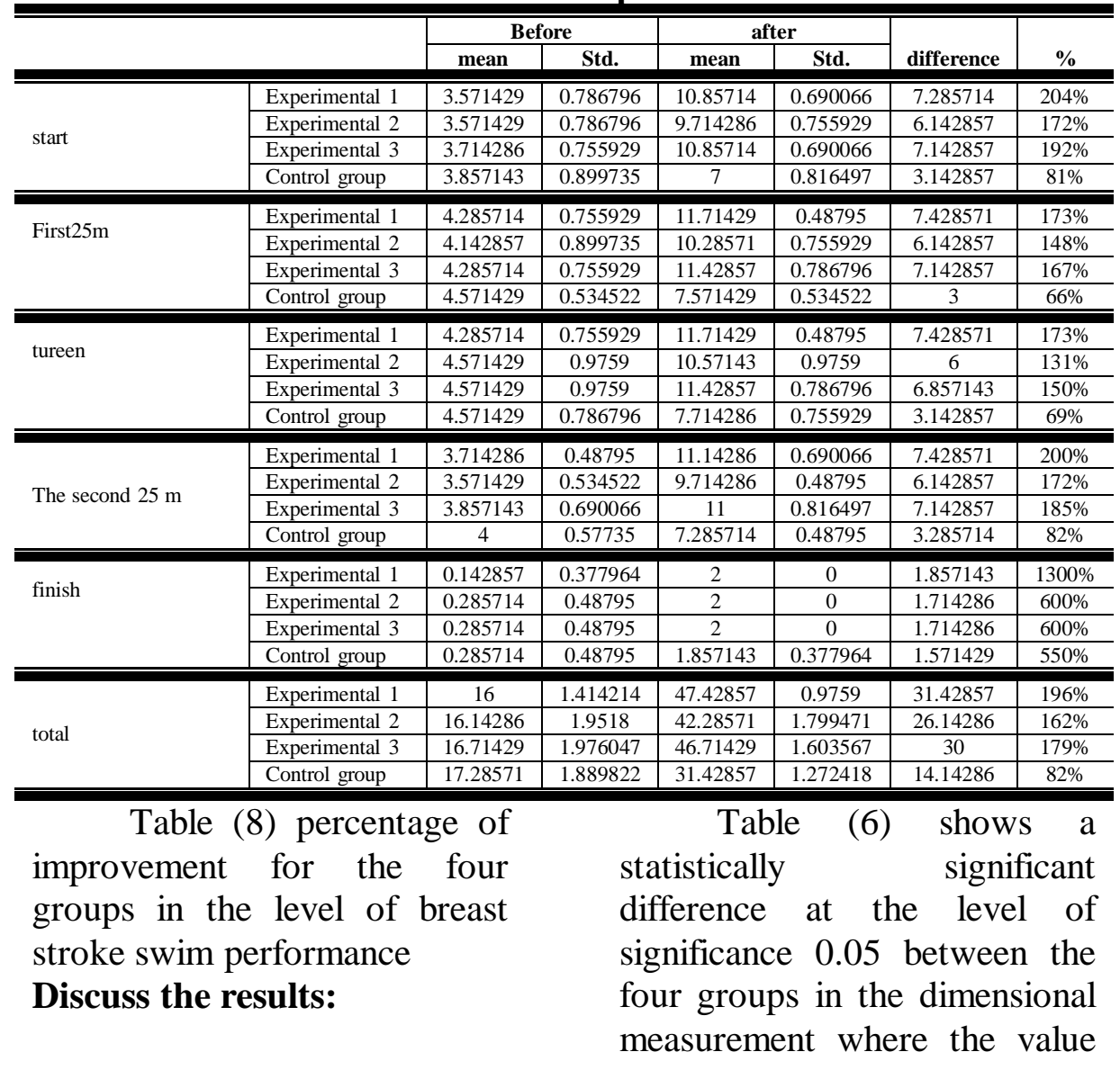


of the calculated $\mathrm{p}$ was greater than the value of the tabular as the value of the statistical significance is smaller than the value of 0.05 except for the end variable

Table (7) shows that there are differences in the means between the first experimental group and the second experimental group and the control in all variables except for the end variable

It is also evident that there are statistically significant differences at the level of 0.05 between the third experimental group and the second experimental group and the control in all variables except for the end variable in favor of the third experimental group

It is also clear from the presence of statistically significant differences at the level of significance 0.05 between the second experimental group and the control group in all variables except for the end variable in favor of the second experimental group

It is also evident that there are no statistically significant differences at the 0.05 specificity level between the first experimental group and the third experimental group in the level of breast stroke swim performance

While it is clear from Table (8) that the first experimental group outperformed all groups in the improvement rate and the third experimental group outperformed the improvement rates over all groups except for the first experimental group while the second group outperformed the control group in the improvement rate

The researcher attributes this improvement to the use of feedback, as using it in its various ways leads to an improvement over the traditional method, as it is characterized by its immediate use during performance to improve the level more than the deferred use after the educational unit or at the beginning of the second unit, due to the importance of feedback and the extent of its effectiveness in skills Kinetic performance that needs high compatibility

This finding is consistent with the study of Magill, R.A. (2001)) (12) Niilo, Knttine. (2004) (13) Ahmed El Sayed Saeed Mohamed Ashmawi (2006) (2) Abdel Wahab 
Kamel (2011) (6) Mohamed Atef Ahmed El Deeb (2012) (13) Esraa Sabry Ahmed Ismail (2013) (3) Abdullah Saad Abdel Gawad: (2017) (7), where all these studies indicated the extent of the effect of the educational program on the level of motor performance with different motor skills under study and the extent of the impact of feedback or reactionary on the level of motor performance of the skills

Conclusions and Recommendations Conclusions:

1- Instant feedback is one of the best ways, means, and methods that can be used in teaching chest swimming

2- Postponed feedback to the next educational unit is better than postponed to the end of the educational unit

3- Deferred feedback to the end of the educational unit is better than traditional methods of teaching swimming pool.

4- Photographing students while they are swimming and displaying them again, and comparing them with the correct performance, motivates students to perform the correct way, then discovering mistakes and quickly fixing them

Recommendations:
1- The necessity of providing different educational means for swimming pools and its divisions of computers, video, cameras and display screens for use in the process of teaching and teaching swimming sports.

2- Focusing on using the feedback method in proportion to the intended skill in the education process to correct mistakes

3 - The necessity of knowing the employees and those in charge of the educational process with different educational methods in order to contribute to delivering the educational information in the shortest time.

4- The necessity of conducting similar studies on the rest of the skills of swimming, water sports and other games

\section{References}

1- Abu Al-Ella Ahmed Abdel-Fattah (1996): 4 x $12=$ 48 to learn swimming, Dar AlFikr Al-Arabi, Cairo.

\section{2- Ahmed El-Sayed Said} Mohamed Ashmawy (2006): "The effect of nutritional feeding on improving the skill performance of the Burmah AlWasat movement for wrestlers. Thesis (MA) - Benha 
University. Faculty of Physical Education for Boys

3- Israa Sabry Ahmed Ismail (2013): The effect of immediate reactionary feeding on the level of performance of the front flip-flop skill on the hands on the horse jumping device for students of the Faculty of Physical Education Thesis (MA) - Helwan University. College of Physical Education for Girls on the island

4- Sahar Abdel Aziz Mohamed (2002): The effectiveness of using minitraining on developing chest swimming skills among students of the Faculty of Physical Education for Girls, Master Thesis, Helwan University.

\section{5- Shams}

Al-Din

Mahmoud (2002): The effect of using a program for special purpose exercises on the level of technical performance of chest swimming for buds, Master Thesis, unpublished, Faculty of Physical Education for Boys in Cairo, Helwan University.

\section{6- Abdel-Wahab Kamel}

(2011): revealing the effectiveness of both cognitive training and vital feedback training and merging them (as an introduction to integrated training in light of the overall model of brain functions) Tanta University, Faculty of Education

\section{7- Abdullah Saad Abdul-}

Jawad: (2017): The effect of using remote feedback on learning some handball skills. The research aims to influence the use of reactionary remote feeding on teaching some handball skills., Thesis (MA) Mansoura University. Faculty of Physical Education

8 -

Ali

Muhammad

Tawfiq (1996): Swimming for Children and Young People, Publishing House, Cairo.

9- Mohamed Atef Ahmed El-Deeb (2012): The effect of using some of the feedback methods to improve performance in sports shows for students of the Faculty of Physical Education for Boys, thesis $(\mathrm{PhD})$ - Tanta University. Faculty of Education

10- Muhammad Ali Al-Qat (2000 AD): $\quad$ Scientific Principles of Swimming, AlAzizi Computer Library, Zagazig.

11- Brooks, Lacne \& Sqwhill (2000) : The Biomechanical Iteraction of lift and Propulsion forces during 
skills breast swimming medicine and science in sport and exercise, 32 (5).

12- Magill, R.A. (2001):

"Feedback effects". In: B.

Singer. H. Hau - senblas \& C. Jannelle (Eds.). Handbook of Sport Ps ychology. 2nd Edition. N. Y. John Wiley \& Sons

13- Niilo, Knttine. (2004): "The effects of augmented auditory feedback on psychomotor skill learning. in precision shoting". Journal of sport and exercise psychology. 26(2). june.

14- Siedentop, D. \& Tannehill n. Kaiso, Mononen. Jukka, viitasalo. Toni, mets. (2004). "Developing Teaching Skills in Physical Education". Mountain View. CA: Mayfield Publishing Company

\section{5- Siedentop,}

D.

Tannehill: (2000). Developing

Teaching skills in physical education. 4th ED. California. Mayfield. 